Tone Smolej

Univerza v Ljubljani

Filozofska fakulteta

tone.smolej@guest.arnes.si
UDK 821.133.1.09-2Molière:821.163.6.09-2Rozman A. DOI: $10.4312 /$ vestnik.7.9-16

\title{
"PREDELUJEM STARE MOJSTRE, K SO JIM ŽE POTEKLE AVTORSKE PRAVICE.« MOLIĖROVA SKOPUH IN NAMIŠLJENI BOLNIK V DRAMSKEM OPUSU ANDREJA ROZMANA
}

$\mathrm{V}$ članku bomo obravnavali Rozmanovo produktivno recepcijo Molièrovega Skopuha (L'Avare) in Namišljenega bolnika (Le Malade imaginaire). Uvodoma pa bomo predstavili tudi slovensko reproduktivno recepcijo omenjenih komedij.

\section{SKOPUH V SKOPUHU}

Čeprav je jurist Konrad Janežič že leta 1888/89 v knjižnem odseku dunajske Slovenije prebiral svoj prevod 4. prizora 3. dejanja, pa njegov poznejši celotni prevod ni bil nikoli uprizorjen. Več kot 30 let je minilo do slovenske praizvedbe: leta 1920 so Skopuha igrali v Trstu v prevodu Friderika Juvančiča. Skopuh je v naslednjih devetdesetih letih doživel 8 inscenacij, prevajalo pa ga je šest prevajalcev (Juvančič, Šnuderl, Kuret, Flere, Moder, Berger), kar je poseben fenomen. Po več kot štirih desetletjih molka je spet spregovoril na kranjskem odru leta 1999 kot Janez Škof v režiji Vita Tauferja. »Tisto, kar je ostalo od Molièrovega Skopuha, so predvsem zaplet in karakterji; nobenega baročnega jezika, vse je postavljeno v gmajn gorenšno, popreproščeno v službi zgodbi in smešnim kolobocijam, «je tedaj zapisal Bogataj (1999: 30).

Rozmanova monodrama Skopuh oziroma »najbolj skopa izvedba Skopuha« je doživela premiero leta 2007. »Resen in sebičen « Harpagon ${ }^{1}$ najprej predstavi glavne probleme slovenske kulture, zlasti davek na knjigo, ter svoje nenavadne patente. Vmes omenja tudi Andra Anzelja, uspešnega poslovneža, ki da je pred leti izgubil družino. Ker mu je dal najnižjo možno obrestno mero, mu je Harpagon takoj ponudil svojo hčerko Elizo: »In kdo ve - mogoče bo pa gospodu Anzelju všeč in ga uspem v svoj sorodstven jarm upreč! In če dobim nega za zeta, postanem član kšnga nadzornga sveta. Predvsem pa pol on za mene garantira in najbrž tud kdaj v kšn moj projekt kej investira.« (Rozman 2009: 52). Ko pa se je hčerka hotela utopit, jo je rešil Valer, ki ga bo očitno treba odstraniti. Sina Kleanta, pesnika, ki pesmi ne piše, da bi kaj zaslužil, pa namerava poročiti z bogato vdovo: »Ona rab mladga,

1 Rozman tu ohranja ime, ki ga je Molière prevzel po latinizmu iz francoskega prevoda Plavtove Aulularie. 
živahnga fanta, on pa za tiskat knige njen dnar in sta idealn par.« (Rozman 2009: 63). A sin si je izbral Marijano, s katero bi se rad oženil tudi oče. Tudi Harpagon se peča z literaturo, saj predeluje stare mojstre, ki so jim potekle avtorske pravice:

In sm se odloču, da bom rajš vzeu eno igro, k se imenuje Skopuh. Ni mi sicr všeč ta beseda, ker se mi zdi precej žaljiva, ker gre za tale sovražni govor in bi blo treba politično korektno igro imenvt Varčnež. Ampak če bo to prnesl več inkasa, se lahko zarad mene imenuje tud Skopuh. Najbl važn je, da mi je glavna vloga čimbl bliz, ker sm namreč tud direktor teatra, kjer morm bit varčen, tko da se bom kot igrauc samo vživu v direktorja in je vloga tko rekoč že narjena in se morm sam še tekst naučit. (Rozman 2009: 64-65).

Ker publika nima drugega dela, kot da čaka, kdaj bo konec, pozove gledalko v prvi vrsti, da mu pomaga. Skupaj bereta prvi prizor iz Skopuha v prevodu Janka Modra, ki je v izvirniku zelo muzikalen in ritmično dovršen (Forestier, Bourqui 2010: 1332):

Vi ste že tle, Valer pa šele pride. Nekolk šepa. Očitno se vrača z rekreacije. Bere iz knjige. »Kako pa to, preljuba Eliza, da postajate otožni, potem ko ste mi še ravnokar ljubeznivo zagotovili, da se zaročite z menoj? Vidim, kako vzdihujete. Joj, pa ravno zdaj, ko sem sam tako vesel! Pa ne da vam je žal, slišite, da ste me osrečili? In da se kesate obljube, h kateri vas je nagnila moja vroča ljubezen? «Zdej pa ste vi. $J i$ šepeta. »Ne, Valer, za nič se ne morem kesati, kar storim za vas. Čutim, kako me vleče v to prečudovita moč, tako da si sploh ne morem želeti, da bi ne bilo tako.« Sej bo šlo. Do Borštnikovga srečanja bova glih v formi. (Rozman 2009: 65 -66).

Vemo, da pri Molièru Anzelm v Valeru prepozna svojega sina, Mariana pa v obeh očeta in brata, kar omogoči dvojno poroko Ta motiv je komediograf prevzel iz commedie dell'arte Izdan (Il tradito), v kateri v Silviu, ki se je udinjal pri Pantaloneju, da bi bil bližje njegovi hčerki, njegov starejši rival prepozna svojega sina. Pri Rozmanu pa se zaplet razreši s telefonskim klicem Elize:

Eliza? Ata tle. Posluš - telefon ni zaston, zato bom kratek. Jutr ob dveh maš za pridt k men, da te predstavm gospodu Anzelju. Kko ga že poznaš? Od Valerja oče? In tud od Marjane oče? Od kere Mar-? Dišamp ... od Kleanta zaročenke ... je našu ugrabljena otroka.. Ampak kako, sej se ona piše Dišamp! Aha - Pokrije slušalko, reče publiki. Kompliciran, ampak logičn. Kaj pa žena? A ženo so pa ubil! Se prav, da se bo spet proču! S tisto vdovo? Trojna poroka ... ja, sej to je najcenej ... (Rozman 2009: 68).

Ker bo z g. Anzeljem v dvojni žlahti, kar mu bo omogočilo investicije, se igra lahko zaključi. Molièrov Harpagon pa terja še vrnitev skrinjice. 


\section{NAMIŠLJENI BOLNIK V HIPOHONDRIJI}

Po neuspehu Smešnih precioz se je prevajalec Juvančič odločil, da bo prevedel še Namišljenega bolnika, ki so ga v Ljubljani uprizorili konec februarja 1908. Kritika je bila navdušena, saj je bila to "prva predstava na slovenskem odru, ki je bila v dekoraciji in igri dosledno stilizirana. Vsa nagajivost, koketna formalnost, umetno stilizirana okretnost $\mathrm{v}$ občevanju za časa Ludvika XIV. se je igralcem neprisiljeno posrečila.« (G. 1908: 4). V istem prevodu so se ob komediji gledalci zabavali v tednu, ko je bila ustanovljena Kraljevina SHS, in še ob tristoletnici Molièrovega rojstva, ko so leta 1922 igro uprizorila vsa tri slovenska gledališča. Novembra 1944 je Namišljenega bolnika uprizorilo še Slovensko narodno gledališče na osvobojenem ozemlju. Najbolj prelomno predstavo je režiral leta 1982 Mile Korun, $\mathrm{v}$ vlogi Argana pa je nastopil Zlatko Šugman. V tej inscenaciji so igrale pomembno vlogo medigre, osebe so se pogovarjale tudi o gledališču, $\mathrm{v}$ določenem trenutku pa so $\mathrm{v}$ dvorano in na oder stopili maskirani igralci in drugi sodelavci pri predstavi (Pogorevc 2011: 12). Skoraj tri desetletja pozneje je Korun isto komedijo postavil še z Borisom Ostanom. Medtem ko se je Šugmanov Argon zavedal lastne minljivosti, je želel Ostanov s preventivo in vnaprejšnjo terapijo prehiteti smrt. $Z$ vseh strani mu oglašujejo zdravje, vendar ga s tem opominjajo na bolezen in smrt in tako v njem rastejo strah, bolezen in tesnoba (Pogorevc 2011: 8). Pod vplivom dekorja francoskih impresionistov je Korun Argona prestavil iz Pariza v hišo na francoski obali (Pogorevc 2011: 11).

Tudi v Rozmanovi komediji Hiphophondrija (hiphop + hipo/hondrija), prvič uprizorjeni leta 2011, je najti junaka, ki mu z vseh strani oglašujejo zdravje. Medtem ko je Molière izbral ime Argan, ki po zvenu nekoliko spominja na Orgona iz Tartuffa, mu je slovenski komediograf dodal črko o in s tem še poudaril značajske poteze Arogana, družinskega očeta, ki je sličen tistemu iz njegovega Tartifa: je brezvesten tajkun, zato tudi podnaslov "patološka burka v ritmu pohlepa«. Če Molièrov lik le zmerja Toineto, se Arogan z gospodinjsko pomočnico Tončko prepira zaradi plače:

Arogan: Kaj če bi se ti brigala za tiste stvari, k jih razumeš! Ti sploh veš, kaj so to strukturni skladi? To so strogo namenska sredstva za zmanjšanje socialnih in regionalnih razlik.

Tončka še vedno meri pritisk : Sej če mi daste plačo, se bo ena razlika zmanjšala. Arogan: Pa ne na tak način. To ne gre kr tko po domače. To je evropski ekonomsko socialni program.

Tončka: Jaz sem slišala, da je namen evropskega ekonomsko-socialnega programa $\mathrm{v}$ tem, da naj bi delo ne zagotavljalo le golega preživetja, ampak tudi dostojno in človeka vredno življenje. (Rozman 2011: 13).

Medtem ko Molièrov Argon sprašuje, če je bil klistir izdaten, in terja, da mu Toineta meša zvarke, je Rozmanov v zahtevah bolj sodoben: »Eno tableto za živce. Pa kisik ukluč, 
pa termometer resetirej, pa pritisk mi zmer, pa napitek zmešej, pa po tale zdravila skoč, pa na ultrazvok me naroč. Pa mir mi dej!« (Rozman 2011: 3).

Tako kot Molièrov je tudi Rozmanov hipohonder, a kritičen do razmer v slovenskem zdravstvu. Zgrožen je, da je lahko samoplačniškega pregleda deležen takoj, z napotnico pa bi bil na vrsti šele čez šest mesecev. Ko izjavi, da je to kriminal, mu hčerka Angelca odvrne, da je to res popolnoma nepošteno do tistih, ki ne morejo plačat in so v neenakopravnem položaju z njim, ki lahko. Arogan hčerko zmerja s komunistko, ona pa mu zabrusi, da je bil tudi sam v partiji. Od svoje hčerke pričakuje, da se bo vpisala na medicino, sama pa bi šla rajši na zgodovino. Prepričan je, da je v družini bolj pomembno imeti zdravnika, saj je zgodovina »že mem. « Pri Molièru se oče in hčerka prerekata predvsem zaradi zaročenca, Argan bi jo rad poročil z zdravnikom.

Pomemben del Molièrovega opusa so t. i. medicinske komedije (Louvat-Molozay 1992: 21). V prvi skupini so komedije, v katerih se osebe le preoblačijo v zdravnike. V Letečem zdravniku (Le Médecin volant) se služabnik, ki hlini, da je zdravnik, pretihotapi do težko dosegljive gospodarjeve izvoljenke, v Don Juanu pa se v zdravnika preoblečeni Sganarel hvali, da je dal kmetom navodila, njegov gospodar pa zabavlja čez zdravnike. V drugi skupini dejansko nastopajo zdravniki. V Ljubezni zdravniku (L'Amour médecin) kopica zdravnikov ne more ugotoviti, da mladenko muči zaljubljenost, v Gospodu pl. Presetniku (Monsieur de Pourceangnac) pa skušajo zdravniki zdraviti popolno zdravega človeka. Prav $\mathrm{v}$ tej komediji spoznamo zdravnika, ki se sklicuje na Galena in njegovo razlago melanholije, ki lahko izvira iz napake v možganih ali iz krvi, nasičene s črnim žolčem, ali pa iz vranice. Zato predlaga puščanje krvi in klistiranje. Molière ugotavlja, da se medicina ni kaj dosti spremenila od časov Galena in Hipokrata, bolezni izvirajo iz krvi ali sokov, zato je treba puščati kri in telo klistirati. V Namišljenem bolniku pa kritizira tudi pariško medicinsko fakulteto, kjer še niso sprejeli teorije krvnega obtoka (Louvat-Molozay 1992: 22). Takšne poglede zagovarja tudi Tomaž Diafoirus, ki skupaj z očetom zdravnikom obišče Arganovo družino, in je zoper obtočnike (les circulateurs) sestavil celo spis. Molière je oba zdravnika karikiral tudi onomastično, saj se v njunem priimku kar dvakrat skriva diareja (dia-rrhée + foir-e + us), ki je nasledek klistiranja (Louvat-Molozay 1992: 50):

Tomaž Diaforus: (Angeliki) Gospa, nebo vam je kot tašči z vso pravico podelilo toliko čara...

Argan: (Tomažu Diaforusu) Saj to ni moja žena; govorite z mojo hčerko.

Tomaž Diafoirus: Kje pa je gospa?

Argan: Takoj bo tukaj.

Tomaž Diafoirus: Ali naj počakam, oče moj, da pride?

Gospod Diafoirus: Ne, izreci svoj poklon gospodični.

Tomaž Diafoirus: Gospodična, čisto tako, kakor se je v Memnonovem kipu, ki 
so ga oblivali žarki sonca, oglasil harmoničen ton, ${ }^{2}$ prevzema mene sladek nemir pri srečanju s soncem vaše lepote. In kakor ugotavljajo naravoslovci, da se cvet, ki se imenuje sončnica, nenehoma obrača proti tej zvezdi dneva, tako se bo poslej moje srce zmeraj obračalo za svetlima zvezdama vaših čudovitih oči kot za svojim edinim tečajem. Dovolite tedaj, gospodična, da položim in darujem na oltarju vaših čarov to srce, ki diha za to in ki ne stremi k ničemur višjemu, kakor da bi smelo biti vse življenje, gospodična, vaš preponižni in nadvse zvesti služabnik in soprog. (Molière: 39-40).

Rozmanova komedija je besedilno najbližje Molièrovi ob nastopu pravkar diplomiranega zdravnika Avgusta Leprovščka, ki pa v imenu skriva latinsko lepro.

Augustulus: Augustulus Leprovšček, doktor medicine. (Tončki da rože.) Tu je skromnih cvetov pet za en sam čudoviti cvet, ki je pognal v ploden svet metulja zrelih moških let, da mu ponudi med in lepša težke dneve.

Tončka: O, najlepša hvala.

Arogan: Spoštovani mladi gospod, ta oseba ni moja žena.

Avgust: O, se opravičujem. A, vi ste... (Tončki vzame šopek in ji da zavojček.) Tu je skromni plod za žlahtni sad, ki kot pomlad, ves svež in mlad, poln še neizpolnjenih upov in nad, želi posejat svoj skriti zaklad in nadaljevat svoj rod. O sad, o plod! O ti, ki nikoli ne padeš daleč proč od drevesa, budnega očesa, ki skrbi, da družinska zgodovinska pot nikoli ne zaide v mrtev kot. O sad, o plod...

Arogan: Spoštovani mladi gospod. Tud moja hčerka to ni.

Avgust: A ja?

Arogan: To je naša gospodinjska asistentka. (Rozman 2011: 14).

Tako kot pri Molièru je tudi pri Rozmanu najti prizor zamenjave ženskih oseb, le da zdaj mladi zdravnik pomeša Belino s Tončko in Tončko z Angelco. V nagovoru Molière uporabi najprej genitivno metaforo (sonce vaše lepote), nato pa še komparacijo sončnice (héliotrope), ki je bila zaradi pretirane uporabe v retorični tradiciji že predmet posmeha (Louvat-Molozay 1992: 112). Pri Rozmanu pa je najti biološko metaforo sadu in ploda, ki namiguje na reprodukcijo.

Zanimiv je tudi odlomek, ko Diafoirus svojega očeta primerja z bodočim Argonom:

Gospod, prišel sem vas pozdravit, zahvalit se vam, vzljubit vas in izkazat vam spoštovanje kot svojemu drugemu očetu, toda očetu, o katerem si drznem reči, da mu moram biti bolj hvaležen kakor prvemu. Prvi me je spočel, vi pa ste me

2 Pri Tacitu je v Analih mogoče brati: »Sicer pa je bil Germanikus pozoren tudi še na druge čudovitosti, med katerimi je bila kamnita Memnonova podoba, ki je zazvenela, kadar so jo zadeli sončni žarki.« (Tacit 1968: 95). 
izvolili. On me je sprejel, ker me je moral, vi pa ste me vzeli k sebi iz milosti. Kar imam od njega, je delo njegovega telesa, kar imam od vas, je delo vaše volje. In kolikor so lastnosti duha višje od telesnih, toliko več vam dolgujem in toliko više cenim vrednost tega bodočega sinovstva, za katero se vam danes globoko občuteno in nadvse spoštljivo klanjam vnaprej. (Molière: 39).

Molière, ki je Plutarha odlično poznal, je takšno primerjavo prevzel iz njegovega življenjepisa Fabija Maksima, ko se Minucij pokloni diktatorju, ki da mu dolguje več kot svojemu roditelju (Rebuffat 1980: 339). ${ }^{3}$ Pri Rozmanu se omenja le še odsotni oče - ugledni profesor: »Sam hodim seveda le po njegovih strokovnih stopinjah in se še kako zavedam, da se še tako bleščeča kariera začne na dnu. Ali kot pravi moj oče, kdor želi na koncu iz čaše slavo piti, mora na začetku brisat usrane riti.« (Rozman 2011: 15).

Omeniti moramo še motiv lažne očetove smrti, ki razkrije prava čustva otrok in pokvarjene žene. Pojavlja se že v napolitanski commedii dell'arte Avaritia, kjer sin objokuje očeta, medtem ko mačeha že hiti overovit oporoko, in v komediji Sinovska ljubezen (L'amor figliale) Jacopa Cigogninija, v kateri druga žena celo škoduje moževemu zdravju (Louvat-Molozay 1992: 18-19). Pri Molièru se slednjič Toaneta preobleče v zdravnika in Arganu veli, naj se dela mrtvega, nato pa novico sporoči Belini: »Čemu je bil sploh na svetu? Vsem v nadlogo, nesnažen, gnusen, večno s klistiro ali kakim zdravilom v trebuhu, človek, ki je ves čas hrkal, kašljal, pljuval ...« (Molière 74). V nasprotju z mačeho pa hčerka objokuje očeta in toži nad svojo usodo.

Tudi Rozman je uporabil podoben motiv, saj se Tončka preobleče v zdravilca in del terapije je tudi navidezna smrt. Belina pa ob novici blekne: »Človk vse organizira, pol pa ta preklet tepec, k ne zna brez teh zdravil, vse pokvar in ti sred posla crkne. Preklet gnoj butast. Kko lahko crkne, predem mu uspem izpult denar.« (Rozman 2011: 34).

Razplet je presenetljiv: Tončka se razkrije kot posebni agent, ki je bil na sledi prevarantke Beline, in na koncu povabi Angelco na hamburger. Pri Molièru pa Argana razglasijo za zdravnika, kar pomeni, da Namišljeni bolnik pripada obema skupinama medicinskih komedij.

\section{SKLEP}

Že Juvan (2000: 268) je Rozmanovega Tartifa označil za travestijo, ki gradivo ubesedi v krepko znižanem slogu, pri čemer povzeto fabulo, junake in predstavljeni svet posodablja, banalizira in familiarizira. Rozman tudi v Skopuhu in Hiphophondriji posodablja Molièrovo zgodbo ter jo močno familiarizira. Harpagon postane sodobni podjetnik, Arogan

3 Minucij takole pravi Fabiju Maksimu: »Naslavljam te plemeniti oče, kajti častitljivejšega naziva ne poznam, ker je ta tvoja usluga večja od mojega očeta. On me je samo spočel, ti pa si moj rešitelj in skupaj z mano tudi rešitelj vseh mojih vojakov.« (Plutarh 2008: 172-173). 
pa tajkun. Krepko znižan slog je poudarjen z ljubljanskim narečjem. Zanimivo, da v prizorih, ki so izrazito prevzeti po Molièru (obisk zdravnika) ali se ga celo dobesedno citira (branje odlomka pogovora med Elizo in Valerjem) slovenski avtor ohranja ali celo uvaja preciozno govorico in se s tem dviga nad prevladujoči slog dialogov oziroma monologa. Omenjeni prizori, ki jih lahko razumemo tudi kot poklon Molièru, delujejo zaradi patetičnega sloga v vsakdanjem okolju veliko bolj smešno kot v francoskem izvirniku.

\section{LITERATURA}

BOGATAJ, Matej (1999) Alpska poskočnica. Razgledi 19, 30.

FORESTIER, Georges/Claude BOURQUI (2010) L'Avare. Notice. Molière. Oeuvres complètes II. Paris: Gallimard, 1313-1334.

JUVAN, Marko (2000) Intertekstualnost. Ljubljana: DZS.

LOUVAT-MALOZAY, Bénedicte (1992) Introduction. Molière. Le Malade imaginaire. Librairie générale française.

P. G. (1908) Slovensko gledališče. Slovenski narod 41/47 (25. 2. 1908), 4.

PLUTARH (2008) Fabij Maksim. Vzporedni življenjepisi. Prevedel Matej Hriberšek. Ljubljana: Modrijan

POGOREVC, Petra (2011/12) Preventiva, terapija, preobrat. Intervju z Miletom Korunom. Gledališki list MGL 1. 7-13.

REBUFFAT, R. (1980) Métamorphose de Fabius cunctator: Thomas Diafoirus. Colloque Histoire et Historiographie. Paris: Les Belles lettres, 335-348.

ROZMAN ROZA, Andrej (2011) Hiphophondrija. Tipkopis.

ROZMAN ROZA, Andrej (2009) Skopuh. Brvi čez morje. Ljubljana: Cankarjeva založba, 43-69.

TACIT (1968) Anali. Prevedel Fran Bradač. Maribor: Založba Obzorja.

MOLIÈRE (1974) Gospod pl. Presetmik. Dela. Prevedel Josip Vidmar. Ljubljana: DZS.

MOLIÈRE (b. 1.) Namišljeni bolnik. Prevedel Josip Vidmar. Tipkopis.

MOLIÈRE (1973) Skopuh. Dela. Prevedel Janko Moder. Ljubljana: DZS.

POVZETEK

»Predelujem stare mojstre, ki so jim že potekle avtorske pravice.« Molièrova Skopuh in Namišljeni bolnik v dramskem opusu Andreja Rozmana.

Avtor v članku obravnava Rozmanovo produktivno recepcijo Molièrovega Skopuha (L'Avare) in Namišljenega bolnika (Le Malade imaginaire). Slovenski komediograf je Skopuha, ki je na Slovenskem doživel vrsto prevodov, leta 2007 predelal v komično monodramo, v kateri je Harpagon podjetnik, ki 
pred občinstvom razpravlja o številnih slovenskih problemih, mimogrede pa omenja še sina in hčer, ki bi ju skladno z ekonomskimi interesi rad poročil. V tej moderni verziji vse pojasni in razreši hčerkin telefonski klic. Leta 2011 je na podlagi Namišljenega bolnika nastala Hiphophondrija, v kateri je družinski oče zgovoren tajkun. Rozman se najbolj približa izvirnemu tekstu v prizoru mladega zdravnika. Oba Rozmanova teksta sta travestiji, saj Molièrovo fabulo ubesedita v znižanem slogu, hkrati pa jo postavita v sodoben slovenski čas. V določenih prizorih, ki so najbližje Molièru, pa se vendar pojavlja preciozna govorica.

Ključne besede: Molière, Rozman, travestija

\section{ABSTRACT \\ "I rework old masters whose copyright has expired." Molière's The Miser and The Imaginary Invalid in the Plays by Andrej Rozman.}

The paper examines Andrej Rozman's creative reception of Jean-Baptiste Poquelin Molière's comedies The Miser and The Imaginary Invalid. The Miser, which had been translated into Slovenian a number of times, was recast in 2007 by the Slovenian comedy writer as a comic one-man play featuring Harpagon as an entrepreneur, who discusses many topical Slovenian problems in front of the audience, with occasional allusions to his son and daughter, whom he wants to marry off according to his economic interests. In this modern version, everything is explained and solved by the daughter's phone call. In 2011, The Imaginary Invalid inspired another of Rozman's plays, Hiphophondrija, which features the family father as a chatty tycoon. Closest to the original is the scene with the young doctor. Both texts are travesties, rendering Molière's plots in a lower register and setting them in contemporary Slovenia. On the other hand, certain scenes which come closest to Molière are couched in 'precious' idiom.

Key words: Molière, Rozman, travesty 